\title{
A study on merger and acquisition in retailing industry of Vietnam
}

\author{
Hong Ngoc Tran ${ }^{1}$, Binh Minh Tran ${ }^{2}$, Manh Dung Tran ${ }^{3}$, Kim Hue Thanh ${ }^{4}$ \\ ${ }^{1}$ Advanced Accounting 59A, National Economics University, Vietnam \\ ${ }^{2}$ Advanced Finance 59A, National Economics University, Vietnam \\ ${ }^{3}$ National Economics University, Vietnam \\ ${ }^{4}$ Banking Academy of Vietnam - Bacninh Campus \\ Corresponding author: Manh Dung Tran. Email: manhdung@ktpt.edu.vn
}

Received 11 November 2020;

Accepted 18 November 2020;

Published 25 November 2020;

\begin{abstract}
This study concentrates on practicing the study of merger and acquisition (M\&A) in Vietnam's retailing industry. It is widely acknowledged that M\&A in the retail industry has been getting more dynamic in recent years as several firms consider M\&A as an ultimate strategy to affirm their positions in the market. In order to achieve the success of an M\&A deal, choosing the right target company and value creation after the deal undeniably is these two pivotal factors. Hence, the study analyzes the M\&A deal which paramount of importance in synthesizing lessons from reality as well as helping entities in the consulting process, then has an ideal tactic to conduct M\&A deals more effectively in the future. This overview reconciles and assimilates the cutting-edge in our comprehension of mergers and acquisitions based on a hugely particular M\&A transaction in the retailing industry among a subsidiary of Vingroup, AEON, Nhat Nam Company.
\end{abstract}

Keywords: Merger and acquisition, retailing industry, Vietnam

\section{Introduction}

Mergers and acquisitions (M\&A) is used to represent the consolidation of companies or assets through numerous types of financial transactions, including mergers, acquisitions, consolidations, tender offers, purchase of assets, and management acquisitions. With an M\&A, investors can enjoy preexisting access to customers, suppliers, and distribution channels. An M\&A can help decrease investment costs, support weak enterprises, and permit new entities to develop and gain a competitive advantage in the market. Notwithstanding a slowdown in global trade and even ASEAN countries experiencing a drop in M\&A activity, Vietnam still ranked the second-highest value of M\&A deals. Thailand, Singapore, South Korea, and Japan are those countries dominating Vietnam's M\&A market in 2018.

Besides, with the fastest-growing middle class in Southeast Asia, Vietnam has been experiencing phenomenal growth rates in its retail sector. The rise of e-commerce and digital retail channels in Vietnam is one of the top trends. Especially, in recent years, Vietnam has had a rapid retail growth. From 2013-2018, the retail sector recorded a compound annual growth rate (CAGR) of $10.97 \%$. Total retail revenue is also expected to reach USD 180 billion by 2020 , which would represent an increase of $26.6 \%$ from 2018. With the influx of investments into the sector, it is poised to witness blooming growth in the near future.Vietnam's retail industry is gradually continuing to see more merger and acquisition (M\&A) deals made by both domestic and foreign investors thanks to a rising income of local consumers and free trade agreements, but the competition in international markets is also becoming fierce. In 2019, Vietnam seized the second spot in the M\&A value rank in Southeast Asia, standing just behind Thailand, which registered $\$ 9.3$ billion and enjoyed a growth of 3.3 percent.

As this is also consistent with the overall M\&A trend around the world, there are various M\&A transactions in retail industry have taken place in Vietnam recently. In particular, the deal of Vincommerce - a subsidiary of Vingroup, acquiring the supermarket chain Fivimart was considered as a ubiquitous M\&A transaction in 2019. That impressive consolidation will be analyzed in this article, particularly, Vincommerce acquired 100 percent of Fivimart in which Aeon mall had owned 30 percent of Fivimart.

\section{Theoretical framework and case studies of sellers \& buyers}

\subsection{Merger \& acquisition theory}

\section{Merger and acquisition classification}

Vertical M\&A is an M\&A activity between two businesses located on the same value chain, leading to the forward or backward expansion of the merged business on that value chain. This form of M\&A is divided into two groups. M\&A forward which occurs when an enterprise conducts an M\&A activity with its client business, for instance, a garment enterprise acquires a clothing retail chain. The other form of M\&A is backward that happens 
when a firm conducting an M\&A activity with its supplier. It is evident that vertical M\&A brings enormous advantages of ensuring and controlling the quality in input or output of products, reducing intermediate costs, controlling the sources of goods or outputs of competitors. Besides, horizontal M\&A is an M\&A activity between two enterprises that do business and compete directly, sharing the same product line and the same market. The results from M\&A activities in this form will bring the merging party the opportunity to expand the market, increase efficiency in brand matching, reduce fixed costs, enhance the efficiency of the distribution system.

Combined M\&A includes all other types of M\&A (usually rarely in form of consolidation). The purpose of M\&A in this form is to minimize risks through diversification, cost reduction and efficiency improvement. Combined M\&A is divided into 3 groups: pure combined $M \& A, M \& A$ expanding geographically and $M \& A$ diversifies products. However, merging $M \& A$ is not as common as the two above methods.

\section{Motivations to promote M\&A activities}

There are various reasons that motivates the buyer to conduct M\&A deal. The cost reduction is not an exception since the M\&A activity incorporates companies reducing the duplication of departments and unnecessary costs, thereby increasing the company's profit margin after M\&A. It is also a great chance for entity to expand their business in marketplace. M\&A will help businesses grasp part or the whole of the supply chain (vertical M\&A) or quickly expand the business line or enter a new business (horizontal M\&A). In addition, M\&A helps organizations utilize available resources including sharing experiences, expertise, research projects, using the sales distribution system.

Reducing competition in a same field is also a huge benefit that companies desire to implement M\&A transaction. Not only do eliminate competitors but also increases competitiveness thanks to economies of scale. Moreover, the competitive position is also enhanced which can force prices with suppliers or monopolize prices with their products. Especially, when a company enter into a new market, performing an M\&A deal with another company doing business in that field is absolutely one of the most effective strategy.

Beside huge advantages of M\&A to buyers, the sellers also find their own motives such as attracting more offers from buyers or finding strategic partners. The motivation to find strategic partners shows the initiative from the seller, it is an essential motivation for businesses in Vietnam to protect themselves against the wave of integration and trade liberalization.

\subsection{Retail industry}

Retail is defined as the activity of selling goods and services to consumers, serving their personal or household use. Retail is considered the last step of the distribution process (Berman and Evans, 2010). There are several ways to classify the retail industry, in which sorting by sales channel is a popular method.

Specifically, when it comes to the Asia-Pacific region, it is impossible not to mention Vietnam, an emerging market as a bright spot in the retail sector, including supermarket retail. In 2018, foreign direct investment (FDI) in Vietnam's retail sector reached 3.67 billion USD, equivalent to $10.3 \%$ of the total foreign direct investment capital for the whole year, ranking the third in value only after the processing, manufacturing and real estate sectors (Pham, 2019).

By the end of 2018, the Vietnamese retail market left an impressive impression with the total retail sales of consumer goods and services reaching a record number of 4,416.6 trillion VND, an increase of $11.6 \%$ over with 2017 (preliminary data of the General Statistics Office). This is a lever to create momentum for Vietnam's retail market to continue to grow in 2019. Total retail sales of consumer goods and services in 2019 marked a new milestone, reaching 4,940.4 trillion VND, an increase of $11.8 \%$ compared to 2018 , the highest growth rate in the 2016-2019 period. The retail goods industry alone had revenue of 3,751.3 trillion dong, accounting for $75.9 \%$ of the total and up $12.7 \%$. In which, the commodity of cultural and educational products increased by $14.4 \%$; food and foodstuff increased by $13.2 \%$; household appliances, tools and equipment up $11.3 \%$;garment increased $10.9 \%$; means of transport increased by $7.8 \%$. The growth of Vietnam's retail market from the beginning of the year up to now shows an increase in consumer demand, an expanding consumer market, and an abundant supply of goods quality is guaranteed, better meeting the needs and tastes of the people.

It is worth mentioning that although global brands and foreign retailers are constantly expanding their influence on the Vietnamese retail market, domestic retailers have risen and improving their competitiveness.

\subsection{AEON Vietnam (Seller)}

AEON Vietnam Co., Ltd, officially established on October 7, 2011, is a member company of AEON Group which is one of the largest retailers in Japan. AEON is a major Japanese retail group with more than 250 years of development. With the potential and experience, AEON mall commit to create comfortable and interesting shopping addresses, pursuing the goal of bringing perfection to customers' lives by providing facilities, goods and services meeting their needs; helping to make lives better.

The main business areas of AEON Vietnam include the construction, management and sales of Shopping mall, Department Store and Supermarket models. In terms of finance, the charter capital of AEON Vietnam is 192,383,000 USD and registered investment capital is 204,648,000 US dollars (Pham, 2019).

In particular, at the time of acquisition, AEON Vietnam operated 4 shopping centers, namely AEON Tan Phu Celadon, AEON Binh Duong Canary, AEON Long Bien and AEON Binh Tan. Normally, AEON Malls will consist of entertainment facilities (indoor facilities to provide entertainment and relaxation space for families, and sports facilities); a Fashion Avenue (offering a look at global fashion trends and suggesting clothing options for daily use); a Beauty Garden (enabling customers to discover the diversity of beauty services), and restaurants. Notably, General Merchandise Stores (GMS) will be available to serve all types of customers. AEON Vietnam owned 30\% of Fivimart's shares before the time of acquisition.

\subsection{Nhat Nam Company (Seller)}

Nhat Nam Joint Stock Company was set up in 1997, is a member of the multidisciplinary corporation TCT Group. Initially, Nhat Nam was established by 14 shareholders, of which TCT Group was the only institutional shareholder and also had the largest ownership rate with $52.7 \%$. In early 2015, AEON Vietnam acquired $30 \%$ shares of Nhat Nam, renamed the supermarket chain to AEON Fivimart. (Nguyen, 2016)

\subsection{Vincommerce (Buyer)}

Vincommerce General Trading Services Joint Stock Company started in 2010 as a member of Vingroup Corporation, the entity that manages the retail segment of consumer goods. It owns a system of VinMart Supermarkets, Convenience Stores / Vinmart + 
Mini Supermarket, VinPro Electronic Center, and Electronic Commerce Website Adayroi. Vingroup's ownership rate in Vincommerce as of the end of 2018 is $64.27 \%$ (Vingroup, 2019). The main business line of Vincommerce include managing and operating supermarket chains. In particular, the Vinmart and Vinmart Plus chains were born in 2014, after acquiring $70 \%$ of the shares of Ocean Retail to hold the right to dominate the Ocean Mart system, marking the group's participation in the retail sector (Pham, 2019)

\section{Consolidated process}

\subsection{Reasons of acquisition}

\section{External factors}

External factor is related to the fresh market trend due to the participation of several foreign companies. Furthermore, the competitiveness created from new foreign firms made M\&A become a blooming trend in domestic. As mentioned before, M\&A brings enormous benefits to entities compared to the traditional one. As the trend has merged and tended to be all the range at that time, there were various acquisitions among foreign companies and Vietnam taken placed. Thailand acquired Big C Vietnam by paying 1.14 billion USD for Casio (France). Another M\&A deal of Saigon Co-op receiving the transfer of the Auchan Reatil Vietnam (France) - retail brand operation at the end of June 2019. Accordingly, Saigon Co.op received all Auchan operations in Vietnam, including: 15 stores operating in retail and e-commerce channels. After the agreement was completed, Saigon Co.op continued to maintain the Auchan brand until the end of February 2020, after which Auchan stores in Ho Chi Minh City. Ho Chi Minh City, Hanoi and Tay Ninh will be selected to convert to the retail brands of Saigon Co.op such as Co.opmart, Co.opXtra or Finelife. Taking over Auchan Vietnam has partly confirmed the strong development of Saigon Co.op in the modern trade field. It can be easily seen that the retailing developed dramatically in recent years with the news of successfully numerous acquisitions. However, the intense competitiveness of this industry requires each corporation to prepare thoroughly to avoid failures. The analysis of Vietnam's retailing industry and supermarket channel will be analyzed below.

Following the Global Retail Development Index which published in mid-2018, consulting firm A.T. Kearney ranked Vietnam in fifth place, up 6 places from the previous year (Nguyen, 2019). Driven by the domestic market's growing purchasing power, the total revenue generated from retail sales and consumer services in Vietnam in 2018 reached VND 4,396 trillion (US\$191 billion), up 11.7 percent compared to 2017. It entirely proves the attractiveness of Vietnamese retail market under the views of foreign investors.

With the growth trend of the retail market, the supermarket retail channel has also had significant growth in recent years. In fact, in Vietnam and neighboring countries in Asia - Pacific, supermarket retail channels have just gradually become popular with consumers. In the past, most of Vietnamese people bought goods through traditional retail channels. A survey conducted by Kantar Worldpanel showed that for every 100 Vietnamese Dong (VND) that a person spend for buying goods, $81 \mathrm{VND}$ are spent in markets, street vendors, mom and pop shops and only 19 VND are spent at the supermarket channel or hypermarket (Pham, 2019) Realizing that potential opportunity in a developing market, a lot of domestic and foreign businesses have participated in the supermarket retail channel in Vietnam.

\section{Internal factor}

(i) Background of Fivimart before the acquisition date

Fivimart's business results were not positive at the time of acquisition. At the beginning of the partnership in 2015, Fivimart had 10 supermarkets, and at that time had 23 stores. However, the first year of cooperation - in 2015, Fivimart reported a loss of VND 60 billion and the following year the loss amounted to VND 96 billion. After two years of cooperation with the Japanese, Fivimart's accumulated loss has increased to 173 billion dong, making the equity of this business just over 30 billion dong by the end of 2016.

In 2017, Fivimart lost VND 23 billion, leading to accumulated losses of VND 197 billion. Only in the first 9 months of 2018 before being acquired, Fivimart's loss before tax soared to VND 558 billion. In addition, the unmanaged shareholder benefit in Nhat Nam is 493 billion dong and goodwill is 901 billion dong. Fivimart's losses in the first nine months of 2018 even far exceed those of previous years. Therefore, it can be summarized that the financial condition of acquired company was really bad with the accumulated losses happened in consecutive years.

\section{(ii) Background of AEON before the acquisition date}

In contrast, AEON has achieved several highlights during the time participating in the Vietnam market. Specifically, the success was recorded mainly in shopping malls. At that time, there were 4 shopping malls which were under the control of AEON with the total $382.780 \mathrm{~m} 2$ of land used. According to a strategy announced by AEON Vietnam, in 2025, there will be 20 center malls named AEON in Vietnam

It is such an incredibly impressive expanding speed of AEON and the flow in revenue of AEON Vietnam obviously is positive. Income before tax in 2017 was 234 billion dong, which is 4.3 times the income of the previous year (Nguyen, 2018). Since the collaboration with Fivimart did not seem to result in a bright future accompanying with AEON mall had aims to expand department stores. It was extremely understandable that in the case of AEON Vietnam stopped investing in Fivimart and left the position of a shareholder. Perhaps the difference in business thinking and strategy makes Aeon still have not found the perfect partner for the past 10 years.

\section{(iii) Background of Vincommerce before the acquisition date}

At the beginning, it is truly acknowledged that Vincommerce regarded $\mathrm{M} \& \mathrm{~A}$ as its key action plan for gaining profit from internal business activities. The list below represents some typical transactions that Vincommerce acquired in the past. In October 2014, Vincommerce bought $70 \%$ shares of Ocean Retail. In January 2015, Vincommerce bought $100 \%$ shares of Vinatexmart and in October of the same year, Vincommerce bought $100 \%$ shares of Maxibank. And in 2018, Vincommerce bought 100\% shares of Fivimart.

Vingroup made good use of M\&A from the first attempt on supermarket retailing. It spent 560 billion Dong for $70 \%$ of Ocean Retail, owner of Ocean Mart and Ocean Mart Express. Ocean Retail was renamed into JSC VinMart, the precursor to Vinmart and Vinmart+. Within a year, Vingroup, again, invested 230 billion Dong to Vinatexmart and 1.835 billion Dong for $100 \%$ of An 
Phong Company, the owner of the supermarket chain Maximark. These companies were merged into Vincommerce (Nguyen, 2016).

\subsection{Milestones in acquisition}

The point of time in the process of acquisition

\begin{tabular}{|l|l|}
\hline $\begin{array}{l}\text { Time } \\
(\mathbf{d d} / \mathbf{m m} / \mathbf{y y y y})\end{array}$ & \multicolumn{1}{|c|}{ Activity } \\
\hline $29 / 01 / 2015$ & $\begin{array}{l}\text { AEON bought } 30 \% \text { shares of Fivimart from } \\
\text { Nhat Nam. }\end{array}$ \\
\hline $08 / 10 / 2018$ & Vingroup bought 100\% shares of Fivimart. \\
\hline $18 / 10 / 2018$ & Nhat Nam was merged into Vincommerce JSC. \\
\hline
\end{tabular}

\section{Results and discussion}

As both buyer and seller have business activities in the supermarket channel retail, it is obviously considered as a horizontal M\&A deal. After buying 100\% of Fivimart, the 23 Fivimart stores would be renamed to Vinmart and has increased the number of supermarkets it owns increase from 74 to nearly 100 (Nguyen, 2018). This acquisition is a part of the plan to expand the number of Vingroup's stores to 200 Vinmart units and 4,000 Vinmart+ convenience stores by 2020 . It can be concluded that the main objective of Vincommerce in this deal is to increase market share through taking over the supermarket system of Fivimart. Vincommerce buyers have certain advantages in the deal when Fivimart is a private enterprise with a rather dense ownership structure, with the two largest shareholders being TCT Group and AEON Vietnam. Concentrated ownership structure of Fivimart, the owner of the company, makes the deal more quickly. The acquisition of Fivimart system, along with previous deals made by Vincommerce such as the acquisition of Ocean Retail and the acquisition of the Shop \& Go, partly revealed the M\&A taste of the business. (Pham, 2019) Those situations express that they focuses on companies that are having financial distress. Simultaneously, Fivimart's business results were not positive at the time of acquisition.

In another acquisition of Vien Thong A mobile phone retail chain, this deal partly reflects the M\&A strategy at the corporate level. Although it is enable to buy desired entities at low prices, Vincommerce in particular and Vingroup generally also face no less than 14 operational and liquidity risks from acquired firms when pursuing this strategy. Henderson (2016) states that an acquisition of a financially distressed business would be a good deal only if the deal itself or the buyer were an immediate solution to the company's problems. It can be seen that Vingroup's management is affirmative in the operating capacity of the supermarket as well as the whole ecosystem. Therefore, achieving synergy is the biggest challenge for Vincommerce when taking over Fivimart. At the time Vincommerce acquired this enterprise, Fivimart was in debt of around US \$ 35.41 million, which is equivalent to the total value of assets (Pham, 2019). This figure is approximately the gross profit of VND 837 billion for the whole of 2017 of Vingroup's supermarket enterprises. It is apparently that cutting management costs, optimizing the supply chain, reversing business advantages of Fivimart will be the priority of Vincommerce. In fact, after the announcement of the deal was only about a month, all 23 Fivimart supermarkets were transformed into Vinmart brands, not only changed the arrangement of the space but they started selling more product of Vingroup such as Vinmart Cook or VinEco, integrates VinID member program for customers.

From a broader perspective, Vincommerce's acquisition of Fivimart directly reflects the consolidation trend of the supermarket retail market in Vietnam, when market share began to fall into the hands of a few businesses. It can be seen that through this deal, Vincommerce increased its market share in the retail channel of supermarket channels from $12.5 \%$ at the end of 2017 to $16.1 \%$ at the end of 2018. At this time, the total market share has 5 businesses in which the largest supermarket chain business (including Saigon Co.op, Vingroup, Mobile World, Dong Hung and SATRA) reached $85.3 \%$. Meanwhile, the total market share of the five largest supermarket chain businesses in 2013 (at this time including Saigon Co.op, SATRA, TCT Group, An Phong and Dong Hung) was only 75.4\% (Pham, 2019).

Vincommerce and Vingroup account business combinations by the purchase method. The total cost of the combination consists of the equity, the fair value of assets and liabilities that assumed or incurred at the time of the date of exchange plus any kinds of expenses occur that belong to the business combination. Moreover, goodwill from a business combination is measured by excess the cost of the combination to the group's interest in net fair value of the assets, liabilities and contingent liabilities of the identifiable assets that have been acquired. When an acquisition happens, Vincommerce and Vingroup evaluate whether the acquisition represents the acquisition of a business, where an integrated set of works is acquired as an addition to the property.

In brief, in the first phase, domestic retailers establish and dominate the market, foreign distributors begin to enter the market. The next phase saw foreign distributors speed up market expansion, while domestic retailers passively waited and observed market movements. Phase 3 is when local retailers wake up and accelerate expansion. Finally, domestic retailers dominate the market. In order to compete and succeed in phases 3 and 4, domestic retailers must know how to exploit and cooperate, creating a resonance of all their strengths. The cooperation between Fivimart and Vingroup can be seen as a sign of the cooperation of domestic retailers to succeed in the third phase of the industry development.

\section{Conclusion and recommendations}

The Vietnamese retail market has a great potential in the future and attracts both domestic and foreign businesses, including Japanese conglomerate AEON. AEON chose M\&A to join the supermarket channel retail segment and acquired $30 \%$ of Fivimart supermarket chain in 2015. By 2018, Vincommerce, a subsidiary of Vingroup acquired $100 \%$ of Fivimart's shares from AEON and Vietnamese partners. In the future, this business should focus on enterprises which have the strength of a commercial center, as well as reconsider plans with convenient store channels and online sales. In addition, AEON Vietnam should regularly focus on improving the customer experience in the shopping centers. Vingroup might also consider vertical M\&A deals with target companies in the field of logistics or supplying agricultural products.

Based on the abovementioned analyses and evaluations, the study has summarized some constructive recommendations for both acquiring and acquired enterprises. First, from seller perspective, choosing the proper objective or partner thorough long-term strategy for the participation in a market. When joining a new market, it is recommended to collaborate with a proper partner or buy shares from a local company to make use of existing resources. Since M\&A requires the suitable decision of choosing partners or firms who share the same vision and direction. Moreover, the usage of resources from both firms also need to be organized effectively. The selling firms should conduct research to define their actual position in Vietnam market. They also should 
reconsider the success probability of other convenient stores as well as e-commerce since it is vital to have abundant capital sources in order to maintain those fields. The seller also notice that there are several reasons for that intense ambiance in the market now such as the struggle of hiring coveted areas, the rocket increase in rent as well as cost which every new store has to face is the low income in the first place. This reality is an explanation for the close of stores owned by big companies after a very short running time.

In terms of acquiring firms, other businesses can learn about Vingroup's M\&A strategy when participating in the retail market. The strategy of acquiring a company then develop it is becoming synonymous over the past few years, and is particularly wellknown with great number of private equity funds (Pham, 2019). The buy and build strategy is implied when a company expands its operations by acquiring a platform company with a developed expertise that it can then build out. Under circumstance that a business requires growth and expansion, there are several possibilities to consider. The company might develop its internal capabilities that will drive the expansion, or the entity can buy a business with an already developed expertise in that area of specialization and build it out further. The effect of M\&A deal can make huge impact on the business based on the valuable contribution of smaller firm. On top of that, the success of M\&A transaction still significantly depends on the proper company platform otherwise it may easily ruin the company with inappropriate strategy.

Overall, there are some particular reasons for M\&A are due to the competition of the supermarket retail market, as well as the negative business results of acquired firm. Furthermore, the cause is that strategic plan of foreign company entering into a new market or the skillful tactic in using M\&A to strengthen the business. In addition, identifying and choosing the right targeted company is extremely an indispensable part when conducting M\&A transactions.

In the future, this business in that field should concentrate on enterprises which have the strength of a commercial center, as well as reconsider plans with convenient store channels and online sales.

\section{Data Availability}

The data, mostly secondary date, was collected based on the sources have been cited and presented in the paper and references. Authors can access the data online.
We - the authors declare that there is no conflict of interest regarding the publication of this paper.

\section{Funding Statement}

The research and publication of our article was funded by ourselves.

\section{References}

[1] AEON Vietnam (2019). AEON foundation. [online] Available at: https://www.aeon.com.vn/lich-su-hinhthanh/ [Accessed 30 Apr. 2019].

[2] Beristain, J.J. (2002). The Place Where Supermarketing Was Born. Mass Market Retailers, 19(9), 172-179.

[3] Berman, B. and Evans, J. (2010). Retail Management: A Strategic Approach. 11th Ed. Prentice Hall.

[4] Henderson, A. (2016). Purchasing distressed businesses: Due diligence tips and financing considerations. Available at: https://assets.kpmg/content/dam/kpmg/ca/pdf/2016/12/pu rchasing-distressed-businesses.pdf [Accessed 30 Apr. 2019].

[5] Deloitte (2019). Vietnam-Consumer-Detail-2019. Walmart Inc. (2019). Walmart 2018 Annual Report. Walmart Inc.

[6] Euromonitor International (2019). Retailing in Vietnam. Euromonitor International.

[7] Nguyen, H. (2016). Almost founding stockholders leaving Fivimart. Available at: http://ndh.vn/hau-het-cacco-dong-sang-lap-deu-da-roi-bo-fivimart-

20161023085941805p4c147.news [Accessed 30 Apr. 2019].

[8] Nguyen, K. (2018). Vingroup acquired Fivimart. Available at: http://cafebiz.vn/vingroup-mua-laifivimart-hon-nhan-voi-dai- gia-nhat-aeon-da-tan-vo20180915093229912.chn [Accessed 30 Apr. 2019].

[9] Nguyen, B. (2016). Vingroup spends more than 18,000 billion Vietnamese dong for M\&A transactions. Available at: https://tuoitre.vn/vingroup-chi-tren-18000ti-dong-cho-cac-thuong-vu- sap-nhap-1087414.htm [Accessed 30 Apr. 2019].

[10] Pham, N.T.N. (2019). Analyzing M\&A transactions in M\&A Contest 2019.

[11] Vingroup (2019). Vingroup 2018 Annual Repor

\section{Conflicts of Interest}

